\title{
Dietary fish oil reduces progression of chronic inflammatory lesions in a rat model of granulomatous colitis
}

\author{
J Vilaseca, A Salas, F Guarner, R Rodríguez, M Martínez, J-R Malagelada
}

\begin{abstract}
Eicosanoids are modulators of defensive and inflammatory processes in the gut mucosa, and may be involved in the pathogenesis of chronic inflammatory lesions of the bowel. As omega-3 fatty acids compete with the omega- 6 as precursors of eicosanoid synthesis, we compared the effects of dietary supplementation with either sunflower (source of omega-6) or cod liver (source of omega-3) oil on the development of chronic granulomatous lesions in the rat colon. After four weeks on the supplemented diets, plasma omega-6 fatty acid content was significantly higher in the sunflower group, while omega-3 fatty acids predominated in the cod liver group. Inflammatory colitis was then induced by intracolonic administration of trinitrobenzene sulphonic acid. Luminal eicosanoid release, as measured by radioimmunoassay of intracolonic dialysis fluid, increased significantly after the challenge in both groups. Generation of prostaglandin $\mathbf{E}_{2}$ $\left(\mathrm{PGE}_{2}\right)$ and leucotriene $\mathrm{B}_{4}\left(\mathrm{LTB}_{4}\right)$ peaked by day 3 and thereafter declined; thromboxane $B_{2}$ $\left(\mathrm{TXB}_{2}\right)$, instead, continued to increase from day 3 to 20 in sunflower fed rats, whereas this change was blunted in cod liver animals. The rats were killed 20,30 , or 50 days after the induction of colitis, and the colonic lesions were scored macroscopically (adhesions to surrounding tissues, strictures, ulcerations, and wall thickness) and histologically (ulceration, inflammation, depth of the lesions, and fibrosis). In cod liver animals, the damage score was markedly reduced by day 30 , and inflammation and ulceration were almost absent by day 50 . In conclusion, a fish oil diet prevents the increase in thromboxane in the chronic stage of inflammation, and shortens the course of the colonic disease by diminishing both the severity of the lesions and their progression to chronicity.
\end{abstract}

The fatty acid composition of marine lipids is markedly different from that of lipids from terrestrial sources. Marine lipids have a higher proportion of long chain polyunsaturated fatty acids called omega- 3 because of the double bond located between the third and fourth carbon atom from the methyl end of the fatty acid chain. Omega-3 fatty acids are scarce in the normal Western diet, which mainly includes polyunsaturated fatty acids from the omega- 6 series. Recent evidence that chronic intake of fish derived omega- 3 fatty acids inhibits neutrophil and monocyte functions ${ }^{12}$ suggests that omega-3 fatty acids may have antiinflammatory proper- ties. Indeed, beneficial effects of marine lipids have been shown in animal models of inflammatory disease, such as carrageenin induced oedema $^{3}$ and murine autoimmune lupus. ${ }^{45}$ In clinical studies, diet supplementation with fish oil has led to symptomatic improvement of active rheumathoid arthritis ${ }^{6}$ and psoriasis.

A hypothetical mechanism that has been proposed to explain these observations is the competition between eicosapentaenoic acid (20:5 omega-3) and arachidonic acid (20:4 omega-6) as precursors of eicosanoid synthesis. Prostaglandins, thromboxane and leucotrienes modulate the inflammatory response. Because the fatty acid composition of diets influences the fatty acid composition of tissues, eicosapentaenoic acid will be released from membrane phospholipids during cell activation. This fatty acid competitively inhibits arachidonic acid metabolism and is transformed into eicosanoid analogues with diminished biological activities when compared with arachidonic acid derivatives. ${ }^{89}$ Thus, dietary fatty acids may influence eicosanoid biosynthesis and modulate the inflammatory response of tissues.

There is evidence that altered eicosanoid generation is a pathophysiological feature of inflammatory bowel disease. Eicosanoid formation is increased in specimens from human diseased tissues ${ }^{10-15}$ and luminal eicosanoid release measured in vivo in patients with active ulcerative rectocolitis is enhanced. ${ }^{16-19}$ Furthermore, recent work from our laboratory with an animal model of inflammatory colitis suggests that thromboxane generation participates in the development of chronic lesions. ${ }^{20}$

The aim of the present study was to investigate the effect of dietary fish oil supplementation on the development of chronic inflammatory lesions in the bowel. We used a rat model based on the intracolonic administration of trinitrobenzene sulphonic acid which induces chronic transmural granulomatous lesions in the colon that develop for several weeks. Mucosal prostanoid release was evaluated throughout the course of the experimental disease by in vivo dialysis of the colon. Morphological damage was also assessed at different stages of the disease and correlated with local eicosanoid generation.

\section{Methods}

\section{ANIMALS AND DIETS}

Male Sprague-Dawley rats weighing 110 to $120 \mathrm{~g}$ were purchased from Interfauna (Barcelona, Spain). The animals were maintained in a 
TABLE I Fatty acid content of the chow pellets

\begin{tabular}{|c|c|c|}
\hline Fatty acid & Sunflower diet & Cod liver diet \\
\hline $14: 0$ & 0.33 & $2 \cdot 88$ \\
\hline $16: 0$ & $4 \cdot 76$ & $10 \cdot 68$ \\
\hline $16: 1$ omega-7 & 0.22 & $5 \cdot 49$ \\
\hline $18: 0$ & $4 \cdot 22$ & 3.51 \\
\hline 18:1 omega-9 & $24 \cdot 34$ & 13.69 \\
\hline $18: 1$ omega-7 & 1.04 & 3.52 \\
\hline $18: 2$ omega- 6 & $51 \cdot 51$ & $12 \cdot 21$ \\
\hline $18: 3$ omega- 3 & 0.78 & $1 \cdot 22$ \\
\hline $18: 4$ omega- 3 & - & $1 \cdot 10$ \\
\hline $20: 1$ omega- 9 & $0 \cdot 24$ & $7 \cdot 57$ \\
\hline $20: 4$ omega- 6 & 0.03 & 0.26 \\
\hline $20: 5$ omega- 3 & - & 5.95 \\
\hline 22:1 omega-11 & - & 5.04 \\
\hline $22: 6$ omega- 3 & - & 6.91 \\
\hline Total & $88 \cdot 77$ & $84 \cdot 90$ \\
\hline
\end{tabular}

Values are expressed as $\mathrm{mg} / \mathrm{g}$ of diet.

restricted access room with controlled temperature $\left(23^{\circ} \mathrm{C}\right)$ and light-dark cycle $(12 \mathrm{~h}: 12 \mathrm{~h})$, and they were housed in rack mounted cages, each containing a maximum of six rats. The experimental diets were prepared using a rodent low fat diet supplemented with $8 \%$ by weight of either sunflower or cod liver oil, as sources of omega- 6 or omega-3 polyunsaturated fatty acids, respectively. Oils were added to the standard mixture during the manufacturing process (Letica, Barcelona, Spain). The final fatty acid content of the pellets was determined by gas chromatography (Table I).

\section{CHRONIC COLITIS}

Colonic inflammatory lesions were induced using the method described by Morris and coworkers. ${ }^{2122}$ The rats were lightly anaesthetised with ether, and $0.25 \mathrm{ml}$ of a solution containing $50 \mathrm{mg}$ trinitrobenzene sulphonic acid (Sigma, La Verpilliere, France) in 10\% ethanol (Merck, Darmstadt, West Germany) were instilled into the lumen of the colon using a rubber cannula ( $7 \mathrm{~cm}$ long, external diameter $2 \mathrm{~mm}$ ) inserted through the rectum. Then, $0.5 \mathrm{ml}$ of air were injected in order to clear completely the trinitrobenzene sulphonic acid ethanol solution from the cannula, and the anaesthetised animals were kept for a few minutes in a supine Trendelenburg position.

\section{EXPERIMENTAL DESIGN}

Seventy rats were included in this study. They were randomly assigned to receive either the sunflower or the cod liver oil supplemented diet and continued on the same diet throughout the experimental period. Five rats from each dietary group were placed in individual metabolic cages to monitor their daily food intake, faecal fat loss and body weight gain. After four weeks, these animals were killed and blood samples obtained for determination of fatty acid levels. All the other rats received an intracolonic injection of trinitrobenzene sulphonic acid for induction of inflammatory colitis, also after four weeks on the experimental diets.

On days $0,3,20,30,40$, and 50 after trinitrobenzene sulphonic acid, animals were subjected to intracolonic dialysis for one hour, under ketamine anaesthesia $(100 \mathrm{mg} / \mathrm{kg}$, ip), to measure luminal eicosanoid release. Ten rats per group, randomly designated before the induction of colitis, were subjected to dialysis on days 3 and 20, and killed on day 20. Another set of 10 rats per group were subjected to dialysis on days 0 and 30 , and killed on day 30 ; and the remainder (seven from sunflower group and six from cod liver group) underwent dialysis on days 40 and 50 , and were killed on day 50. As previously described, ${ }^{20}$ dialysis bags were prepared using Visking seamless cellulose tubing $(8 / 32,6.3 \mathrm{~mm}$ diameter, $7 \mathrm{~cm}$ long) attached via a $10 \mathrm{~cm}$ rubber cannula to an external syringe. After inserting the entire cannula into the distal colon, the dialysis bag was filled with $1 \mathrm{ml}$ dialysis solution, consisting of $0.3 \%$ bovine serum albumin in a $\mathrm{NaCl} 120 \mathrm{mM}-\mathrm{KHCO}_{3} 30 \mathrm{mM}$ solution adjusted to $\mathrm{pH} 7 \cdot 90$. One hour later, the fluid was withdrawn and immediately stored at $-30^{\circ} \mathrm{C}$ until assayed.

On days 20,30 , and 50 , six to 10 rats per group, as described above, were killed by cervical dislocation. The distal colon was removed, opened longitudinally, rinsed with normal saline and pinned out on synthetic cork. Mucosal damage was assessed macroscopically and the whole piece was then fixed in a solution containing $2 \%$ formaldehyde and $1 \%$ glutaraldehyde ${ }^{23}$ for later histological assessment.

\section{ASSESSMENT OF COLONIC LESIONS}

The macroscopically visible damage was assessed with a stereomicroscope by two observers unaware of the experimental group. Each colon was assigned a score on a scale ranging from 0 to 10 based on the criteria stated in Table II, which note colonic adhesions to surrounding tissues, strictures, mucosal ulcerations, and wall thickening.

For the histological studies, samples were processed by routine techniques before embedding in paraffin. Sections were stained with haematoxylin and eosin and coded for blind examination. Each slide was assigned a score on a

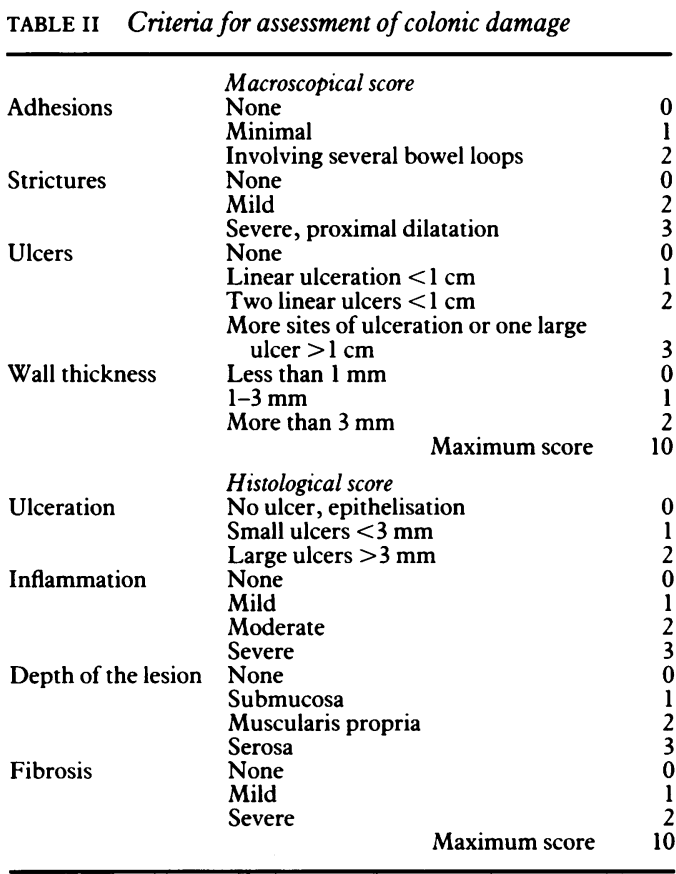


scale ranging from 0 to 10 based on the presence of ulcerations, degree of inflammation, depth of the lesions and presence of fibrosis (Table II).

FATTY ACID ANALYSIS

The analytical procedure has been extensively described recently. ${ }^{2+}$ Briefly, total fatty acid methyl esters were obtained by direct methanolysis of the samples (100 $\mu \mathrm{l}$ plasma, and about $100 \mathrm{mg}$ chow pellet) with $2 \mathrm{ml} 1.4 \mathrm{M} \mathrm{HCl}$ according to Lepage and Roy, ${ }^{25}$ after addition of an appropriate amount of $13: 0$ as internal standard $(100 \mu \mathrm{g}$ for plasma and $500 \mu \mathrm{g}$ for chow pellet). The fatty acid methyl esters were then separated by capillary column gas chromatography on a $30 \mathrm{~m}$ long, $\mathbf{0 . 2 5} \mathrm{mm}$ id, SP2330 fused silica capillary column (Supelco, Bellefonte, PA), operated on a two step temperature programme $\left(140\right.$ to $180^{\circ} \mathrm{C}$, at $4^{\circ} \mathrm{C} / \mathrm{min} ; 180$ $210^{\circ} \mathrm{C}$, at $1.5^{\circ} \mathrm{C} / \mathrm{min}$ ) and installed in a Hewlett Packard 5890 gas chromatograph, equipped with flame ionisation detectors. The carrier gas was helium, with a column pressure of $17 \mathrm{psi}$ (corresponding to a flow of about $1 \mathrm{ml} / \mathrm{min}$ ), and the split ratio varied between $20: 1$ and $50: 1$, depending on the amount of fatty acid methyl esthers injected. Injector and detector temperatures were $200^{\circ} \mathrm{C}$ and $220^{\circ} \mathrm{C}$, respectively. The peak areas were measured with a Merck-Hitachi D-2000 integrator and quantified on a weight basis by the internal standard method. Identification of the peaks was carried out by comparison with authentic standards, whenever possible, and/or with mixtures of known fatty acid and aldehyde composition. Otherwise, fatty acids were identified by the equivalent chain length approach. ${ }^{26}$

\section{EICOSANOID RADIOIMMUNOASSAYS}

Eicosanoid concentrations in the dialysates were measured by specific radioimmunoassays for prostaglandin $\mathrm{E}_{2} \quad\left(\mathrm{PGE}_{2}\right)$, thromboxane $\mathbf{B}_{2}$ $\left(\mathrm{TXB}_{2}\right)$, and leucotriene $\mathrm{B}_{4}\left(\mathrm{LTB}_{4}\right)$. Tritiated standards were purchased from Amersham International (Buckinghamshire, UK). Antisera for $\mathrm{PGE}_{2}$ and $\mathrm{LTB}_{4}$ measurements were kindly donated by Dr J A Salmon (Wellcome Research Laboratories, Beckenham, UK). Samples were

levels after four wa fally aci sunflower or cod liver oil supplemented diet. Five rats per point (mean SEM))

$(\star)$ denotes $p<0.05$ between sunflower and cod liver fed animals. For simplicity only major fatty acids are

labelled.

$\mathrm{mg} / \mathrm{dl}$

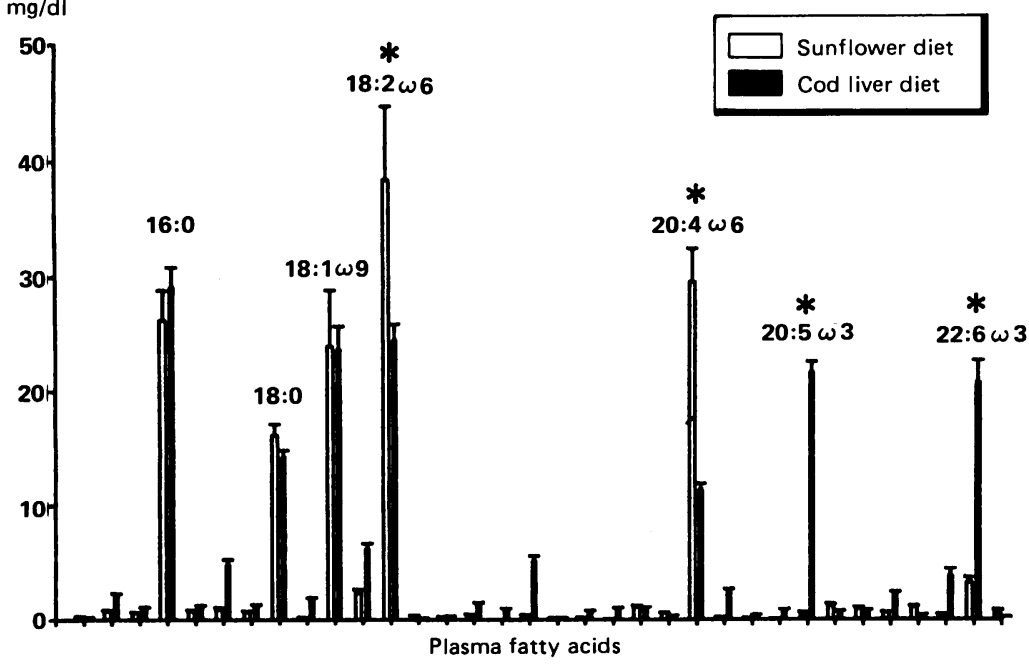

diluted 1:10 to 1:25 in assay buffer and measured without prior extraction and HPLC-purification. Crossreactivity of $\mathrm{PGE}_{3}$ with the $\mathrm{PGE}_{2}$ antiserum is $14.0 \%$; $\mathrm{LTB}_{5}$ crossreacts with the $\mathrm{LTB}_{4}$ antiserum at $17 \cdot 1 \% .^{9}$ Authentic $\mathrm{TXB}_{3}$ was not available. Antisera, radioimmunoassay and HPLC methods have been previously described in detail. ${ }^{27-29}$

\section{Statistical analysis}

Results are presented in graphs and Tables as mean standard error of the mean (SE). The statistical difference between means was determined by the Student's $t$ test for unpaired data.

\section{Results}

EFFECTS OF DIET ON BODY WEIGHT AND PLASMA FATTY ACIDS

Both diets were well tolerated by the laboratory animals. During the first week on diet, daily food intake averaged $18.8(2 \cdot 1) \mathrm{g}$ in the sunflower group and $19.8(1.8) \mathrm{g}$ in the cod liver group. Animals fed the sunflower diet had a body weight gain of 22.9 (5.1) g/week on the first week, which was similar to that achieved by cod liver fed rats $(21 \cdot 3(3 \cdot 6))$. There was no significant difference in body weight between the two experimental groups after four weeks on diet. Faecal fat was undetectable in all samples.

Plasma fatty acid concentrations are shown in Figure 1. Sunflower fed rats had significantly
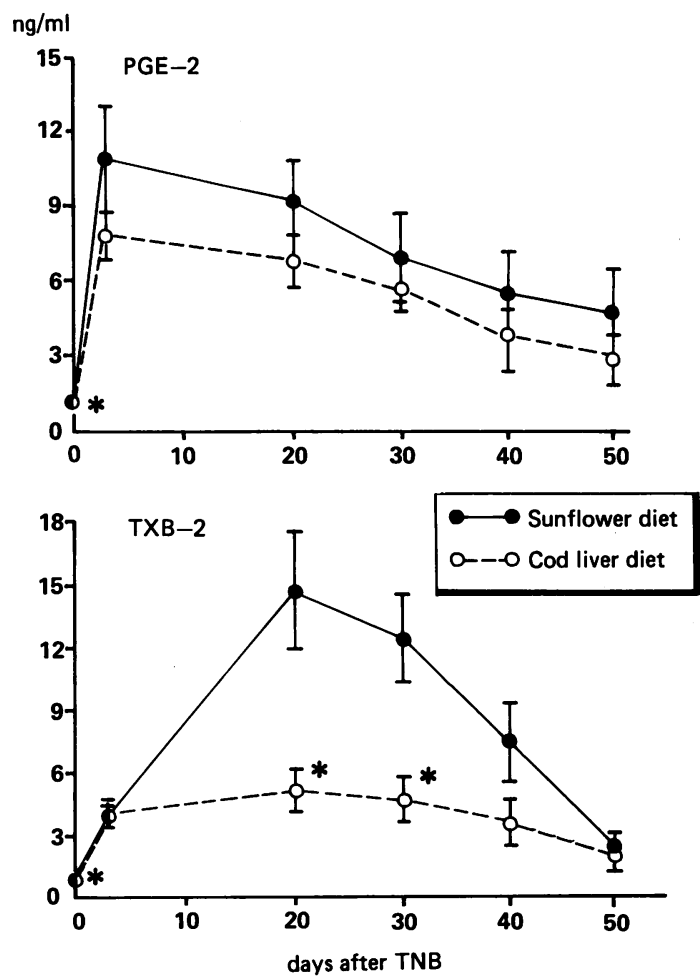

Figure 2: Changes in luminal release of $P G E_{2}$ (upper panel) and $T \mathrm{XB}_{2}$ (lower panel) after the induction of colitis by intracolonic administration of trinitrobenzene sulphonic acid on day 0. Values represent $\mathrm{ng} / \mathrm{ml}$ of fluid obtained after one hour of in vivo dialysis of the colon, as described in Methods. Ten rats per points (mean (SEM)) but on days 40 and 50, in which seven rats from sunflower group and six rats from cod liver group were subjected to dialysis. $\left.{ }^{\star}{ }^{\star}\right)$ denotes $p<0.05$ between sunflower and cod liver fed animals. 
higher levels of linoleic acid (18:2 omega-6) and arachidonic acid (20:4 omega-6) than cod liver fed animals. As expected, the cod liver group showed high levels of omega- 3 fatty acids (eicosapentaenoic acid, 20:5 omega-3, and docosahexaenoic, 22:6 omega-3) which were almost absent in sunflower rats.

\section{CHANGES IN PROSTANOID SYNTHESIS \\ DURING THE COURSE OF \\ TRINITROBENZENE SULPHONIC ACID \\ COLITIS}

Before the induction of colitis, luminal release of $\mathrm{PGE}_{2}, \mathrm{TXB}_{2}$, and $\mathrm{LTB}_{4}$, as measured by intracolonic dialysis, was higher in sunflower fed animals $\left(\mathrm{PGE}_{2}\right.$ : $1.092(0.218) \mathrm{ng} / \mathrm{ml} ; \mathrm{TXB}_{2}$ : $\left.0.905(0.150) ; \mathrm{LTB}_{4}: 0.167(0.034)\right)$ than in the cod liver group $\left(\mathrm{PGE}_{2}: 0.565(0.082) \mathrm{ng} / \mathrm{ml}\right.$; TXB $_{2}: 0.590(0.101) ;$ LTB $_{4}: 0.082(0.021)$, $\mathrm{p}<0.05)$. After the challenge with trinitrobenzene sulphonic acid, all three eicosanoids studied significantly increased in the dialysates from both groups of rats.

As shown by Figure 2, luminal release of $\mathrm{PGE}_{2}$ and $\mathrm{TXB}_{2}$ changed as time elapsed from trinitrobenzene sulphonic acid instillation. For $\mathrm{PGE}_{2}$, peak release occurred earlier (around day 3 after trinitrobenzene sulphonic acid) than for $\mathrm{TXB}_{2}$ (around day 20 after trinitrobenzene sulphonic acid). For $\mathrm{PGE}_{2}$, there were no significant differences between both experimental diets throughout the study, although mean concentrations in the dialysis fluid from sunflower fed rats were always above those detected in cod liver fed rats. In contrast, luminal release of $\mathrm{TXB}_{2}$ markedly increased from day 3 to days 20 and 30 in sunflower fed rats but this change did not occur in cod liver fed animals. Hence, significant differences between sunflower and cod liver group occurred on days 20 and 30 .

Changes in the intracolonic release of $\mathrm{LTB}_{4}$ were similar in both groups of rats. In the sunflower group, concentrations increased from day $0(0.167(0.034) \mathrm{ng} / \mathrm{ml})$ to day $3(5.965$ $(1 \cdot 316))$ and there was no further increment on day $20(5 \cdot 787(1 \cdot 870))$. Cod liver fed rats showed a similar pattern (day 0: $0.082(0.021)$; day 3: $6.441(1.016))$, and mean levels on day $20(3.674$ $(0.573))$ were lower than in sunflower rats, though the difference was not significant. Dialysis fluid samples from days 30,40 , and 50 were not assayed.

CHANGES IN COLONIC MORPHOLOGY Figure 3 depicts the mean macroscopical and histological scores obtained from rats killed on days 20, 30, and 50 after trinitrobenzene sulphonic acid. On day 20, macroscopical damage scores were significantly lower in cod liver animals than in sunflower group, but there was no difference in the histological scores. With the progression of the inflammatory colitis, differences between both experimental groups became more evident and cod liver fed rats showed lower macroscopical and histological lesion scores than sunflower fed rats. By day 50, inflammation and ulcerations were almost absent in cod liver fed animals, while the sunflower

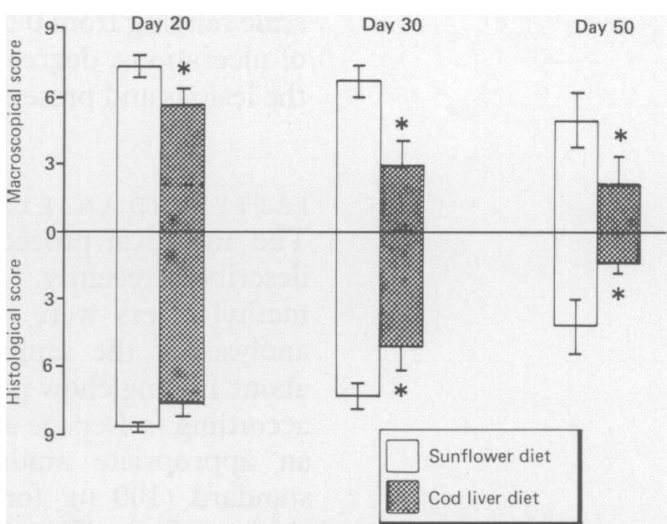

Figure 3: Morphological lesion scores of colonic damage induced by trinitrobenzene sulphonic acid, assessed according to the criteria shown in Table II. Means (SEM) are shown; $(\star)$ denotes $p<0.05$ between sunflower and cod liver fed animals.

group still showed flaring mucosal lesions. Thus, the initial injury was similar in both groups of rats, but the development of chronic inflammatory lesions in the colon was mitigated by the cod liver diet.

\section{Discussion}

The aim of the present study was to investigate whether changes in the type of dietary fat would influence eicosanoid synthesis and modify the progression of chronic inflammatory lesions in the bowel. The experiments described in this paper show that a fish oil diet mitigates the severity of chronic inflammatory lesions induced by trinitrobenzene sulphonic acid in the colon, while reducing the intracolonic release of thromboxane during the chronic phase of the disease.

Two special diets were prepared for this study using a standard low fat diet that was supplemented either with sunflower or cod liver oil. Both diets were isocaloric and thus the body weight gain and the daily intake of food were similar in both groups of rats. Therefore, it is unlikely that the beneficial effects of the cod liver oil diet were the result of a difference in caloric consumption. The two experimental diets differed, however, in their content of polyunsaturated fatty acids, as the sunflower diet was rich in omega- 6 fatty acids and the cod liver diet in omega-3 fatty acids. As shown in Figure 1, the plasma fatty acid concentrations of the animals after four weeks on the experimental diets reflected these differences accordingly. Thus, differences in lipid composition between the two diets are most likely responsible for the variances noted in the expression of the colonic disease. Previous studies showed antiinflammatory effects of dietary omega-3 fatty acids, ${ }^{3-7}$ and our findings expand this concept to the field of inflammatory lesions of the bowel.

The mechanism by which omega- 3 fatty acids would have a beneficial influence on inflammatory diseases is not certain. This class of fatty acids compete with the omega- 6 as precursors of eicosanoid synthesis and, in our study, eicosanoid formation by the colonic mucosa was modified by the cod liver diet. Before the induction of colitis, luminal release of $\mathrm{PGE}_{2}, \mathrm{TXB}_{2}$, 
and $\mathrm{LTB}_{4}$ was significantly lower in cod liver fed animals than in the sunflower group. After the administration of trinitrobenzene sulphonic acid, colonic eicosanoid generation rose in all animals and immediate differences between groups were not apparent. During the chronic stage of the inflammatory lesions, however (days 20 and 30 after the challenge), luminal thromboxane release was significantly lower in cod liver than in sunflower fed rats. Because eicosapentaenoic acid derived eicosanoids $\left(\mathrm{PGE}_{3}\right.$ and $\mathrm{LTB}_{5}$ ) may interfere in the assay by crossreaction with the antibodies, it is probable that actual $\mathrm{PGE}_{2}$ and $\mathrm{LTB}_{4}$ levels in the cod liver group were below the estimated figures. In any event, a key finding in our study was that thromboxane release was qualitatively as well as quantitatively different in the cod liver group when compared with the sunflower group. Thus, the time course of thromboxane stimulation showed a distinct profile in cod liver fed rats, characterised by a blunting of the increase in thromboxane release during the chronic stage of inflammation that occurred in the sunflower group.

The source of thromboxane in inflammatory exudates has been investigated in an experimental model. ${ }^{30}$ While thrombocytopaenia did not affect thromboxane concentration in inflammatory exudates, it was shown that neutropaenia reduced thromboxane by $95 \%$ and other prostaglandins to a lesser extent. Thromboxane but not $\mathrm{PGE}_{2}$ concentrations correlated closely with total leucocyte numbers in exudates, suggesting that migrating white blood cells are the major source of thromboxane in inflammation, while local cells or tissues also contribute to the synthesis of $\mathrm{PGE}_{2}$. Thromboxane is the predominant cyclooxygenase product synthesised by all types of circulating leucocytes, ${ }^{31}$ and activates macrophages and polymorphonuclear leucocytes. ${ }^{32}$

Whether thromboxane synthesis contributes to the formation of chronic inflammatory lesions in the bowel, ${ }^{20}$ cannot be inferred from the present study. A decreased thromboxane release in cod liver fed rats during the chronic stage of colonic inflammation, however, probably reflects either reduced tissue infiltration by inflammatory white cells or decreased activity of the infiltrating white cells. The histological studies on day 20 after trinitrobenzene sulphonic acid did not show significant differences between both experimental groups, and there is no basis for the assumption that the number of infiltrating leucocytes was less prominent in cod liver fed rats. It seems more likely that migrating white cells exhibited a lower degree of activation in the cod liver group than in sunflower fed rats. Reduced inflammatory activity of the infiltrating cells would explain the mitigated course of chronic inflammatory lesions in the cod liver group, as observed on days 30 and 50 after trinitrobenzene sulphonic acid. Several lines of evidence point towards an inhibitory effect of dietary omega- 3 fatty acids on neutrophil and monocyte functions, such as neutrophil aggregation, chemotactic response to peptides or $\mathrm{LTB}_{4}$, adherence to endothelial cells and interleukin-1, and tumour necrosis factor production by stimulated peripheral-blood mononuclear cells. ${ }^{1-233}$ Our findings would be consistent with these observations.

In summary, the present study suggests that dietary supplementation with a fish oil rich in omega-3 fatty acids palliates the progression of chronic inflammatory lesions in the trinitrobenzene sulphonic acid model of granulomatous colitis, and shortens the course of the disease. The beneficial effects are associated to a reduction of thromboxane release during the chronic stage of the inflammatory lesions. The clinical relevance of these observations on lipid dietary modification for the management of chronic inflammatory bowel disease is still uncertain, but preliminary data have already suggested a beneficial effect of eicosapentaenoic acid supplements on human chronic ulcerative colitis. ${ }^{34}$ Additional controlled clinical trials are needed to corroborate these preliminary clinical observations and to put the potential value of such therapeutic approach in perspective.

Part of this study was presented at the Annual Meeting of the American Gastroenterological Association, May 1989, Washington, DC. The authors wish to thank Ms Celia Liria and Mrs Dolors Soldevila for their excellent technical assistance. This Investigaciones Sanitarias de la Seguridad Social, Spain.

1 Lee TH, Hoover RL, Williams JD, et al. Effect of dietary enrichment with eicosapentaenoic and docosahexaenoic acids on in vitro neutrophil and monocyte leukotriene generation and neutrophil function. $N \mathrm{Engl} \mathcal{F} \mathrm{Med} 1985$; 312: 1217-24.

2 Mehta JL, Lopez LM, Lawson D, Wargovich TJ, Williams LL. Dietary supplementation with omega-3 polyunsaturated fatty acids in patients with stable coronary heart disease. Effects on indices of platelet and neutrophil function and exercise performance. Am $\mathcal{F}$ Med 1988; 84: 45-52.

3 Terano T, Salmon JA, Higgs GA, Moncada S. Eicosapentaenoic acid as a modulator of inflammation. Effect on prostaglandin and leukotriene synthesis. Biochem Pharmacol 1986; 35: 779-85.

4 Kelley V, Ferretti $\dot{A}$, Izui A, Strom TB. A fish oil diet rich in and suppresses lupus in MRL-lpr mice. $\mathcal{f}$ Immunol 1985; and suppresses

5 Robinson DR, Prickett JD, Makoul GT, Steinberg AD, Colvin RB. Dietary fish oil reduces progression of established renal disease in $(N Z B \times N Z W) F_{1}$ mice and delays renal disease in BXSB and MRL/1 strains. Arthritis Rheum 1986; 29: 539-46.

6 Kremer JM, Jubiz W, Michalek A, et al. Fish-oil fatty acid supplementation in active rheumatoid arthritis. A doubleblinded, controlled, crossover study. Ann Intern Med 1987; 106: 497-503.

7 Bittiner SB, Tucker WF, Cartwright I, Bleehen SS. A double blind, randomised, placebo-controlled trial of fish oil in psoriasis. Lancet 1988; i: 378-80.

8 Needleman P, Raz A, Minkes MS, Ferrendeli JA, Sprecher H. Triene prostaglandins: prostacyclin and thromboxane biosynthesis and unique biological properties. Proc Natl Acad synthesis and unique biologi
Sci USA 1979; 76: 944-8.

9 Terano T, Salmon JA, Moncada S. Biosynthesis and biological activity of leukotriene $B_{5}$. Prostaglandins 1984; 27: 217-32.

activity of leukotriene $B_{5}$. Prostaglandins 1984; 27: 217-32.
10 Sharon $P$, Ligumsky $M$, Rachmilewitz D, Zor U. Role of prostaglandins in ulcerative colitis. Enhanced production
pron prostaglandins in ulcerative colitis. Enhanced production
during active disease and inhibition by sulfasalazine. Gastroenterology 1978; 75: 638-40.

11 Ligumsky M, Karmeli F, Sharon P, Zor U, Cohen F, Rachmilewitz D. Enhanced thromboxane $\mathrm{A}_{2}$ and prostacyclin production by cultured rectal mucosa in ulcerative colitis and its inhibition by steroids and sulfasalazine. Gastroenterology 1981; 81: 444-9.

12 Hawkey CJ, Karmeli F, Rachmilewitz D. Imbalance of prostacyclin and thromboxane synthesis in Crohn's disease. Gut 1983; 24: 881-5.

13 Boughton-Smith NK, Hawkey CJ, Whittle BJR. Biosynthesis of lipoxygenase and cyclo-oxygenase products from [14]Carachidonic acid by human colonic mucosa. Gut 1983; 24: 1176-82.

14 Sharon P, Stenson WF. Enhanced synthesis of leukotriene $B_{4}$ by colonic mucosa in inflammatory bowel disease. Gastroenterology 1984; 86: 453-60

15 Peskar BM, Dreyling KW, Peskar BA, May B, Goebell H. Enhanced formation of sulfidopeptide-leukotrienes in ulcerative colitis and Crohn's disease: inhibition by sulfasalazine and 5-amino salicylic acid. Agents Actions 1986; 18: $381-3$.

16 Lauritsen K, Hansen J, Bytzer P, Bukhave K, Rask-Madsen $J$. Effects of sulphasalazine and disodium azodisalicylate on colonic $\mathrm{PGE}_{2}$ concentrations determined by equilibrium in vivo dialysis of faeces in patients with ulcerative colitis and healthy controls. Gut 1984; 25: 1271-8. 
17 Lauritsen K, Laursen LS, Bukhave K, Rask-Madsen J. Effects of topical 5-aminosalicylic acid and prednisolone on prostaglandin $E_{2}$ and leukotriene $B_{4}$ levels determined by equilibrium in vivo dialysis of rectum in relapsing ulcerative colitis. Gastroenterology 1986; 91: 837-44.

18 Lauritsen K, Laursen I.S, Bukhave K, Rask-Madsen J. In vivo effects of orally administered prednisolone on prostavivo effects of orally administed prednisolone on prosta1987; 28: 1095-9.

19 Lauritsen K, Laursen LS, Bukhave K, Rask-Madsen J. In vivo profiles of eicosanoids in ulcerative colitis, Crohn's vivo profiles of eicosanoids in ulcerative colitis, Crohn's
colitis and Clostridium difficile colitis. Gastroenterology colitis and 1988 ; 95 : $11-7$.

20 Vilaseca J, Salas A, Guarner F, Rodríguez R, Malagelada JR. Participation of thromboxane and other eicosanoid synthesis in the course of experimental inflammatory colitis. Gastroenterology 1990; 98: 269-77.

21 Morris GP, Beck PL, Herridge MS, Depew WT, Szewezuk MR, Wallace JL. Hapten-induced model of chronic inflammation and ulceration in the rat colon. Gastroenterology 1989 96: 795-803

22 Boughton-Smith NK, Wallace JL, Morris GP, Whittle BJR. The effect of anti-inflammatory drugs in a chronic model of The effect of anti-inflammatory drugs in a chronic model of inflammato $65-72$.

23 McDowell EM, Trump BF. Histologic fixatives suitable for diagnostic light and electron microscopy. Arch Pathol Lab diagnostic light and electr
Med 1976; 100: 405-14.

24 Martínez M. Polyunsaturated fatty acid changes suggesting a new enzymatic defect in Zellweger Syndrome. Lipids 1989 24: $261-5$
25 Lepage G, Roy CC. Direct transesterification of all classes of lipids in a one-step reaction. F Lipid Res 1986; $24: 114-20$ 26 Jamieson JR. Glc identification techniques for long-chain
unsaturated fatty acids. $\mathcal{f}$ Chromat $S c i$ 1975; 13: 491-7.

27 Ahlquist DA, Duenes JA, Madson TH, Romero JC, Dozois RR, Malagelada JR. Prostaglandin generation from gastroduodenal mucosa: regional and species differences. Prostaglandins 1982; 24: 115-25.

28 Guarner C, Colina I, Guarner F, Corzo J, Prieto J, Vilardell F. Renal prostaglandins in cirrhosis of the liver. Clin Sci 1986; 70: $477-84$

29 Salmon JA, Simmons PM, Palmer PMJ. A radioimmunoassay for leukotriene $B_{4}$. Prostaglandins 1982; 24: 225-35.

30 Higgs GA, Moncada S, Salmon JA, Seager K. The source of thromboxane and prostaglandins in experimental inflammation. Br f Pharmacol 1983; 79: 863-8.

31 Morley J, Bray MA, Jones RW, Nugteren DH, Van Dorp DA. Prostaglandin and thromboxane production by human and guinea-pig macrophages and leukocytes. Prostaglandins 1979; 17: 730-6.

32 Spagnuolo PJ, Ellmer JJ, Hassid A, Dunn MG. Thromboxane $\mathrm{A}_{2}$ mediates augmented polymorphonuclear leukocyte adhesiveness. 7 Clin Invest 1980; 66: 406-14.

33 Endres S, Ghorbani R, Kelley VE, et al. The effect of dietary supplementation with $n-3$ polyunsaturated fatty acids on the supplementation with n-3 polyunsaturated fatty acids on the
synthesis of interleukin-l and tumor necrosis factor by mononuclear cells. N Engl f Med 1989; 320: 265-71.

34 McColl T, O'Leary D, Bloomfield J, O'Morain CA. Eicosapentaenoic acid [A Bstract]. Gastroenterolog $v$ 1988; 94: A294. 